\title{
A paradigm shift in the provision of improved critical care in the emergency department
}

\author{
KM Yim *, HF Ko, Marc LC Yang, TY Li, S Ip, J Tsui
}

\section{A B S T R A C T}

With Hong Kong's ageing population, advancement of medical technologies and hospital congestion, it is not uncommon for emergency physicians to encounter complicated critically ill patients in daily practice. It becomes a fundamental role of emergency physicians to initiate timely diagnostic and therapeutic interventions to save a patient's life and improve their prognosis. It is the reason a critical care service has been developed in emergency departments worldwide over the last decade. This article shares how emergency department intensivists can contribute to this novel model of care with some illustrative cases. Advanced airway and peri-intubation management, difficult mechanical ventilation, treatment of shock, circulatory arrest, and metabolic disturbances can be safely and efficiently handled in the current emergency department setting. Obstacles, barriers, and the road ahead will be discussed.

\section{Hong Kong Med J 2018;24:293-7}

DOI: $10.12809 / \mathrm{hkmj} 176902$

\author{
1,2 KM Yim *, MB, ChB, FHKCEM \\ ${ }^{1}$ HF Ko, MB, BS, FHKCEM \\ ${ }^{1}$ MLC Yang, MB, ChB, FHKCEM \\ TY Li, MB, BS, FHKCEM \\ ${ }^{1} \mathrm{~S}$ Ip, APN \\ J Tsui, APN \\ ${ }^{1}$ Accident and Emergency Department \\ 2 Intensive Care Unit \\ Queen Elizabeth Hospital, Jordan, Hong Kong \\ * Corresponding author: anferneeyim@gmail.com
}

\section{Introduction}

The provision of a critical care service in the emergency department (ED) was once considered synonymous with an intensive care unit (ICU). Nonetheless with more and more critically ill patients presenting to the ED, it is not uncommon for them to remain there for the first 1 to 2 hours of treatment. Examples include patients with out-of-hospital cardiac arrest and post-arrest care, septic shock, and status asthmaticus. In addition, ICU overcrowding results in some patients with relatively less critical disease entities such as diabetic ketoacidosis or hypokalaemia being triaged out from ICU admission. Nonetheless these patients still require close monitoring and intervention that are beyond the capacity of a general medical ward. It would be ideal for this group of patients to receive the same evidence-based aggressive intensive care measures regardless of their location within the hospital. An emergency department intensivist (EDI) can provide such care. Emergency department intensivist refers to a dually qualified emergency medicine (EM) and intensive care fellows who practises ED critical care as part of their clinical role. ${ }^{1}$

The development of an intensive care subspecialty under the umbrella of emergency medicine is increasing rapidly around the world. For example, such combined training is provided by the Australian College of Emergency Medicine and College of Intensive Care Medicine of Australia, the Royal College of Emergency Medicine and the Faculty of Intensive Care Medicine in the United Kingdom, as well as the American Board of Internal Medicine, American Board of Emergency Medicine, and American Board of Medical Specialties in the United States. In our region, emergency physicians in mainland China, Taiwan, Singapore, Japan, and Macau are providing a critical care service in their EDs and some are even running their separate Emergency-ICU as well. As one of the preeminent medical hubs in Asia, we followed the trend several years ago. We have a well-established training pathway in Hong Kong for those wishing to attain dual fellowship qualification in EM and intensive care medicine (ICM). A memorandum of understanding was signed between the Hong Kong College of Anaesthesiologists and the Hong Kong College of Emergency Medicine in 2012. In order to become a dually qualified EDI, an Emergency Medicine fellow is required to complete a 2-year rotation in an accredited ICU and 1 year in an accredited anaesthesia training centre. The trainee should fulfil the training requirements of the ICM programme including regular tutorials, research projects, and success in a final examination to obtain the dual qualification.

By bringing intensive care monitoring and therapies to the ED, EDI may provide timely, life-saving treatment to critically ill patients and mitigate the negative effect of ICU overcrowding 


\section{在急症室提供進階危重病監護方面的 創新醫學模式}

嚴建明、高曉輝、楊聿川、李天恩、葉少華、崔崇山

隨着香港人口老化和醫療技術進步, 醫院床位愈見緊迫, 急症室醫生 在日常工作中遇到複雜的危重病人並不罕見。急症室醫生適時的診斷 和治療, 對挽救病人的生命並改善預後有着基礎性作用。這是在過去 十年中全球急診部門發展危重病監察護理服務的原因。本文以過往病 例, 分享已完成危重病科訓練的急症專科醫生如何為這種新型監護模 式作出貢獻。在目前的急診室設置中, 完成危重病科訓練的急症專科 醫生可以安全有效處理進階氣道處理, 複雜的呼吸機使用及機械通 氣、休克治療、心藏驟停和代謝紊亂等急重症。本文亦討論此監護模 式遇到的障礙和前路。

by reducing the number of patients who progress to multi-organ dysfunction and reducing the need for ICU admission. ${ }^{2,3}$ Nonetheless international studies have emphasised that most EDs have not been designed or staffed to provide care beyond the initial resuscitation period in the first 20 to 60 minutes. ${ }^{4,5}$ Our ED has been transformed over the last few years to overcome such limitations. Examples include an expanded and dedicated resuscitation area in the ED; provision of the ability to perform basic hemodynamic monitoring, including measurements of arterial blood pressure, non-invasive cardiac output monitoring device, echocardiogram machines; mechanical ventilation capability, including high flow nasal cannula and conventional ICU ventilator; and an exchange programme for ED nursing staff so that they may develop proficiency

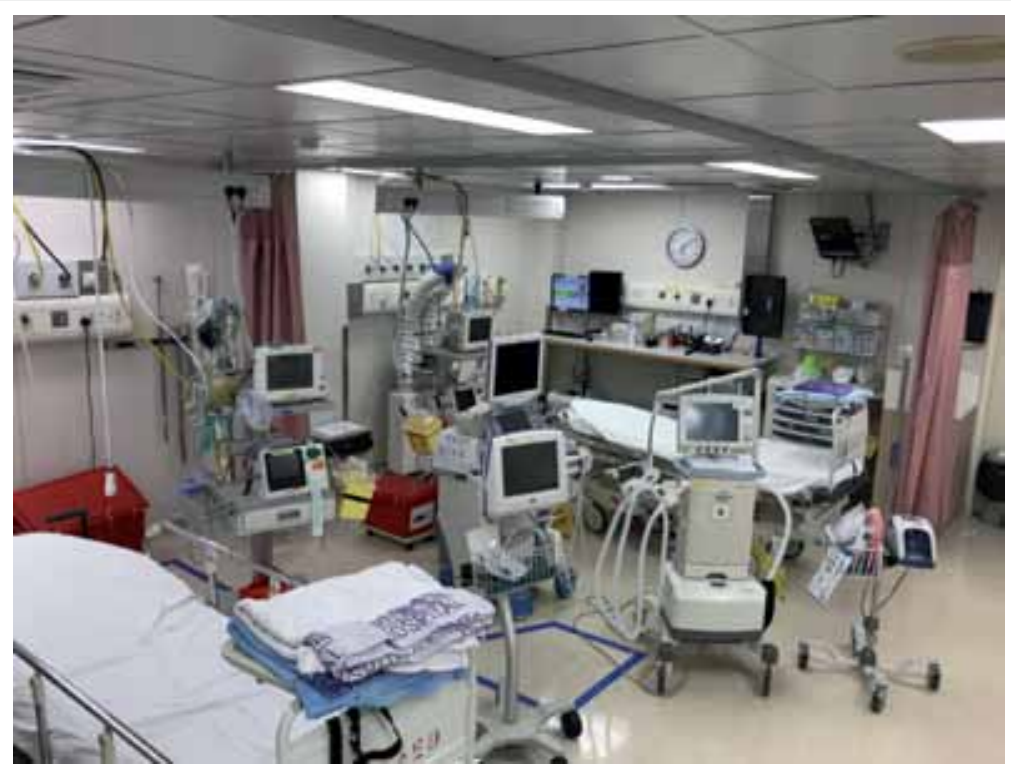

FIG. Extended resuscitation area for patients requiring intensive care in the emergency department of Queen Elizabeth Hospital in haemodynamic monitoring and mechanical ventilation.

\section{Hybrid and resource intensivist models}

There are two models of practice of EDI worldwide: the resource intensivist model and the hybrid model. In the former, the EDI plays a standard clinical role in the specialist roster of ED. Whenever a critically ill patient presents to the department, the EDI can provide additional expertise either as the primary physician or as an adviser. This has the benefit of exposing all clinical team members to the same level of care. It is similar to the toxicology model in the ED wherein the toxicologist can improve an entire department's care of poisoned patients. The presence of EDIs may lead to similarly improved management. In the hybrid model, the ED resuscitation area is transformed to act as an ED-ICU. In this model, the EDI can easily shift the abilities of this resuscitation area to allow for the care of critically ill patients beyond the first hour and provide a similar intensity of care to that available in the ICU. ${ }^{1}$

Our department adopts a mixed resource intensivist and hybrid model of care. Three of the four qualified EDIs in Hong Kong work in the department and act as resource intensivists. From November 2016, our department commenced provision of an ED specialist-led service specifically for all critically ill patients who presented to our resuscitation room between 08:00 and 18:00 on weekdays. About one third of such duties were assumed by the three EDIs, providing other clinical team members with opportunities to keep up-to-date with their skills, knowledge, and practice of managing critically ill patients. Physically, we have an expanded and dedicated area (Fig) that can care for up to six critically ill patients at any one time. Emergency department intensivists may decide the level of care required and this will depend on the clinical situation of the patient and review of the available resources and administrative considerations. At other times, EDIs are assigned duties in the normal EP roster. Emergency department intensivists can also provide on-site advice to emergency physicians upon request. The critical care team endeavours to incorporate critical care skills into routine ED practice, such that manpower utilisation is optimised and patient workflow is not altered. The team can function as a bridge that enables better communication between the ED and the ICU. Quality assurance is achieved by regular critical care audits, research, and sharing of local and international experience.

\section{Extended triage and advanced resuscitation strategy}

We aimed to adopt an extended triage strategy. 
This involves the targeting of critically ill patients who require close monitoring with timely initiation of resuscitative and therapeutic measures in the presence of a readily reversible condition. Examples include metabolic diseases such as diabetic ketoacidosis and severely poisoned patients. The primary goal is to institute early aggressive therapy and monitoring. The patient can either be escalated to care in the ICU if a suboptimal response to therapy is evident, or admitted to a general ward if they show signs of recovery. Overseas study has quoted a $11.1 \%$ reduction in ICU admissions (patients were instead admitted to the general ward) after therapy was administered in the ED. It proved a preventive role of the ED in disease progression and ICU resource utilisation. $^{6}$

The increasing complexity of critically ill patients demands sophisticated skills and knowledge, both in the early diagnostic process and initial management. Examples include refractory septic shock, acute respiratory distress syndrome, and refractory cardiac arrest. Emergency department intensivists can provide advanced resuscitation to those patients in the ED who are awaiting ICU admission. It is well established that more rapid and aggressive treatment of sepsis and septic shock patients can reduce in-hospital mortality. ${ }^{7}$ The objective of advanced resuscitation is to stabilise acute physiological derangement, working up the underlying causes of acute deterioration, and initiating timely life-sustaining therapies. The following clinical case of septic shock illustrates how the EDI can integrate critical care into ED practice.

We were referred a 40-year-old female with multi-lobar pneumonia and septic shock from a nearby private hospital in February 2017. Intensive care unit staff were immediately consulted and agreed to take the patient. Since an isolation facility was not immediately available within the ICU, it was expected that the patient would remain in the ED for at least 2 hours. On presentation, her saturation was $85 \%$ in a non-rebreathing mask, respiratory rate was $40 / \mathrm{min}$, and she was in distress. Her blood pressure was $80 / 50$ $\mathrm{mm} \mathrm{Hg}$ and heart rate $130 / \mathrm{min}$. Chest X-ray showed diffuse bilateral infiltration. After performing rapid sequence intubation with adequate pre-oxygenation, she remained in profound septic shock. The EDI managed her according to the latest Surviving Sepsis Campaign Guideline. ${ }^{8}$ The management strategy in the first 3 hours of presentation included adequate fluid resuscitation, lactate measurement, blood culture, and administration of a broad-spectrum antibiotic. Fluid responsiveness was frequently assessed by bedside echocardiography. Despite these measures that also included 2 litres of crystalloid, the patient remained hypotensive. Non-invasive blood pressure monitoring may not be optimal in this setting. Once thought to be within the ICU domain, arterial blood pressure monitoring is now readily available in ED. An arterial line can provide continuous blood pressure readings for vasopressor titration as well as enable the EDI to obtain valuable information about fluid responsiveness and perform frequent blood sampling. An arterial line and a central venous catheter were inserted into the patient using an aseptic technique and ultrasound guidance in accordance to international guidelines. ${ }^{9}$ Noradrenaline was the vasopressor of choice and the dose was titrated to maintain mean arterial pressure above $65 \mathrm{~mm} / \mathrm{Hg}$. Ceftriaxone was administered at a door-to-needle time of 30 minutes after blood culture. The first point-of-care lactate level was $6 \mathrm{mmol} / \mathrm{L}$. After nearly 2 hours of aggressive resuscitation, the patient was transferred to ICU for further management. The lactate level on arrival was $3 \mathrm{mmol} / \mathrm{L}$, demonstrating a significant improvement in perfusion. Urine pneumococcal antigen was positive. She was weaned off the vasopressor on day 2, and she was extubated and discharged to the general ward on day 3 .

We have also encountered other clinical cases where the extended triage and advanced resuscitation approach were adopted. A brief period of intensive therapy in the ED can alter the clinical trajectory with improved outcome and reduced resource utilisation for many crashing patients in the ED who have readily reversible conditions, eg, acute pulmonary oedema, diabetic ketoacidosis, and hypokalaemic periodic paralysis. Emergency physicians possess the skills required for airway management in the majority of patients and an EDI can lend additional support. This is especially true for those patients with a difficult airway, as well as hypoxic and hypotensive patients. ${ }^{10-16}$ Use of ventilation strategies in patients with respiratory failure are also within the realm of the EDI, eg, intubated asthmatic patients with high airway pressure connected to an ICU ventilator. ${ }^{17,18}$

Extracorporeal cardiopulmonary resuscitation (ECPR) describes the application of percutaneous extracorporeal life support to the arresting patient, and aims to improve the survival to hospital discharge rate in cardiac arrest. ${ }^{19}$ Over the past decade, it has emerged as a salvage therapy in patients with refractory cardiac arrest. An algorithm has been described that involves screening of patients by an emergency physician for their suitability for ECPR, rapid access to the femoral vessels, and initiation of bypass in appropriate cases, without interruption of optimal traditional resuscitative efforts. ${ }^{20}$ The role of EDIs in this critical moment cannot be overemphasised. Since all EDIs have received extracorporeal life support (ECLS) training during their pursuit of ICU fellowship, they can liaise with intensivists in the identification of suitable candidate patients following application of strict inclusion/exclusion criteria, supervise 
ongoing resuscitation, as well as perform vascular cannulation. We recently initiated ECPR on a 40-year-old male in January 2016, with a history of diabetes and hypertension and witnessed cardiac arrest in the ED. The time to ECPR activation was 20 minutes from cardiac arrest. The time to establishment of an ECLS circuit was 50 minutes. Although the patient succumbed 3 days later due to advanced triple vessel disease not amenable to percutaneous coronary intervention or surgery, this case illustrates how the EDI can contribute to this novel therapeutic option in selected patients.

\section{The obstacles that we are facing}

Providing critical care in the ED is a paradigm shift in the local ED setting. There remains much to be learned.

Emergency department overcrowding and staff shortages are the main obstacles to the provision of a critical care service in the ED. Many will argue that stabilising the critically ill patient in ED will slow their transfer to ICU. Resources may be directed to these patients while the care of non-critically ill patients will be compromised. Departmental leaders are reluctant to place an additional burden on staff who already have an overwhelming workload, especially during admission blocks and long waiting time. A separate medical and nursing staff roster for critically ill patients may alleviate the problem. Others may argue that critical care in the ED should be provided by in-patient intensivists who come down to the ED. Nonetheless with a scarcity of intensivists throughout the territory as well as a tremendous workload, this may not be possible.

Leaders' initiatives, colleagues' acceptance, and devotion of emergency physicians are the keys to success. Even with adequate staffing, the meticulous management requirements in the care of critically ill patients do not appeal to some emergency physicians. $^{2}$ In addition to regular departmental case conferences and in-house training, a course on emergency care of critically ill patients will be organised on a regular basis by the Hong Kong College of Emergency Medicine for doctors and nurses who work in the ED. The course will be tailormade to suit the unique Hong Kong ED environment. Emergency care of critically ill patients focuses on initial stabilisation and advanced resuscitation techniques with lectures, simulations, and handson workshops. Through education and experience sharing, more and more emergency physicians may choose to join us to provide evidence-based aggressive care for critically ill patients in their own ED.

\section{Conclusion}

The benefits of providing critical care in the ED in reducing ICU length of stay and reducing ICU admission have been illustrated by studies in the United States. ${ }^{3,6}$ Nonetheless local data are lacking. There is a need to conduct research in order to convince administrators that more proximal delivery of critical care in the ED, before ICU admission, may decrease downstream ICU costs and yield significant system savings.

We established a critical care registry in January 2017 for critically ill patients who present to our ED. A total of 100 cases were seen in 6 months. The outcome can be quantified by measuring patient improvement in physiological parameters using Acute Physiology and Chronic Health Evaluation II, Simplified Acute Physiology Score II, and Multiple Organ Dysfunction Score during their ED stay. ${ }^{3}$ Intensive care unit length of stay and mortality can be evaluated in future cost-effectiveness analyses. ${ }^{21,22}$ Hopefully, as data accrue, many of the perceived advantages of early critical care in the ED will be proven and accepted.

\section{Declaration}

All authors have no conflicts of interest to disclose. All authors had full access to the data, contributed to the study, approved the final version for publication, and take responsibility for its accuracy and integrity.

\section{References}

1. Weingart SD, Sherwin RL, Emlet LL, Tawil I, Mayglothling J, Rittenberger JC. ED intensivists and ED intensive care units. Am J Emerg Med 2013;31:617-20.

2. Gupta R, Butler RH. Fellowship training in critical care may not be helpful for emergency physicians. Ann Emerg Med 2004;43:420-1.

3. Nguyen HB, Rivers EP, Havstad S, et al. Critical care in the emergency department: a physiologic assessment and outcome evaluation. Acad Emerg Med 2000;7:1354-61.

4. Gill FJ, Leslie GD, Grech C, Latour JM. A review of critical care nursing staffing, education and practice standards. Aust Crit Care 2012;25:224-37.

5. Goldstein RS. Management of the critically ill patient in the emergency department: focus on safety issues. Crit Care Clin 2005;21:81-9.

6. Rivers EP, Nguyen HB, Huang DT, Donnino MW. Critical care and emergency medicine. Curr Opin Crit Care 2002;8:600-6.

7. Seymour CW, Gesten F, Prescott $\mathrm{HC}$, et al. Time to treatment and mortality during mandated emergency care for sepsis. N Engl J Med 2017;376:2235-44.

8. Rhodes A, Evans LE, Alhazzani W, et al. Surviving sepsis campaign: international guidelines for management of sepsis and septic shock: 2016. Intensive Care Med 2017;43:304-77.

9. American Society of Anesthesiologists Task Force on Central Venous Access, Rupp SM, Apfelbaum JL, et al. Practice guidelines for central venous access: a report by the American Society of Anesthesiologists task force on Central Venous Access. Anesthesiology 2012;116:539-73.

10. Heffner AC, Swords DS, Nussbaum ML, Kline JA, Jones AE. Predictors of the complication of postintubation 
hypotension during emergency airway management. J Crit Care 2012;27:587-93.

11. Heffner AC, Swords DS, Neale MN, Jones AE. Incidence and factors associated with cardiac arrest complicating emergency airway management. Resuscitation 2013;84:1500-4.

12. Ramkumar V, Umesh G, Philip FA. Preoxygenation with $20^{\circ}$ head-up tilt provides longer duration of non-hypoxic apnea than conventional preoxygenation in non-obese healthy adults. J Anesth 2011;25:189-94.

13. Weingart SD, Levitan RM. Preoxygenation and prevention of desaturation during emergency airway management. Ann Emerg Med 2012;59:165-75.e1.

14. Baillard C, Fosse JP, Sebbane M, et al. Noninvasive ventilation improves preoxygenation before intubation of hypoxic patients. Am J Respir Crit Care Med 2006;174:1717.

15. Wimalasena Y, Burns B, Reid C, Ware S, Habig K. Apneic oxygenation was associated with decreased desaturation rates during rapid sequence intubation by an Australian helicopter emergency medicine service. Ann Emerg Med 2015;65:371-6.

16. Sakles JC, Mosier JM, Patanwala AE, Arcaris B, Dicken JM. First pass success without hypoxemia is increased with the use of apneic oxygenation during rapid sequence intubation in the emergency department. Acad Emerg Med 2016;23:703-10.

17. Mannam P, Siegel MD. Analytic review: management of life-threatening asthma in adults. J Intensive Care Med 2010;25:3-15.

18. Leatherman JW, McArthur C, Shapiro RS. Effect of prolongation of expiratory time on dynamic hyperinflation in mechanically ventilated patients with severe asthma. Crit Care Med 2004;32:1542-5.

19. Ortega-Deballon I, Hornby L, Shemie SD, Bhanji F, Guadagno E. Extracorporeal resuscitation for refractory out-of-hospital cardiac arrest in adults: a systematic review of international practices and outcomes. Resuscitation 2016;101:12-20.

20. Bellezzo JM, Shinar Z, Davis DP, et al. Emergency physicianinitiated extracorporeal cardiopulmonary resuscitation. Resuscitation 2012;83:966-70.

21. Cowan RM, Trzeciak S. Clinical review: emergency department overcrowding and the potential impact on the critically ill. Crit Care 2005;9:291-5.

22. Huang DT. Clinical review: impact of emergency department care on intensive care unit costs. Crit Care 2004;8:498-502. 